\title{
Neuroendocrine Regulation of Seasonal Breeding Cycles in the Ewe
}

\author{
FRED J. KARSCH AND SUZANNE M. MOENTER \\ Reproductive Sciences Program, and Department of Physiology, \\ The University of Michigan, Ann Arbor, Michigan 48109
}

\begin{abstract}
Seasonal reproduction has emerged as an important topic of investigation which bridges the areas of endocrinology, neurobiology, biological rhythms, and fertility regulation. Among the species in which this topic has been studied, the sheep has proven to be especially useful for investigating the neuroendocrine mechanisms which underlie the seasonal switches in fertility. This is due to a number of attributes. One of these is the large blood volume of sheep which permits extensive sampling for characterizing pulsatile patterns of hormone secretion. Another attribute is the large size of its brain and pituitary gland which facilitates complex neurosurgical procedures such as those required for collecting hypothalamic-pituitary portal blood for measurement of hypophysiotropic substances. Based on work in sheep, it has become evident that pulsatile secretion of luteinizing hormone $(\mathrm{LH})$ from the anterior pituitary is driven by an episodic discharge of gonadotropin-releasing hormone ( $\mathrm{GnRH})$ from the hypothalamus, and that seasonal reproduction results largely from alterations in the pulsatile pattern of LH release. By using the sheep as a model, it should now be possible to elucidate the neural mechanisms which underlie these seasonal alterations in the reproductive neuroendocrine axis.
\end{abstract}

\section{SEASONAL REPRODUCTION AS A RESEARCH TOPIC}

Investigation into the biological phenomenon of seasonal reproduction, and its underlying regulatory mechanisms, has become an active area of endocrine and neuroendocrine investigation. The importance of this area stems, in large measure, from the fact that seasonal breeding constitutes a natural process of reversible fertility displayed by most species of vertebrates living in temperate regions. It is thought that an understanding of how this process is achieved will lead to new approaches of fertility regulation in species which are important for the production of food, fibers, and furs, and in the human population as well.

Studies in the area of seasonal reproduction have focused on a wide variety of topics. These include description of the organization of seasonal breeding cycles; identification of environmental cues which regulate the process; elucidation of the neurobiological pathway for perception and processing of those environmental cues; investigation into the physiological and morphological adaptations which produce the switches in reproductive competence; characterization of the endocrine and neuroendocrine mechanisms which lead to these adaptations; and determination of the role played by biological rhythms (ultradian, circadian, circannual) in the production and temporal organization of seasonal reproductive cycles. Many different species of seasonal breeders have been used to investigate this spectrum of topics. Among these species, several have emerged as being particularly useful as animal models for the specific areas indicated above.

This report focuses on the use of the sheep as an animal model for studying seasonal reproductive cycles. Some of the attributes and limitations of this species and those areas of investigation for which this model is particularly well suited will first be considered. Examples of specific uses of this model will then be described. Finally, perspectives and approaches for future research will be considered.

\section{THE SHEEP AS AN ANIMAL MODEL}

The sheep has proven to be especially well suited for investigating the endocrine and neuroendocrine basis of the seasonal switches in fertility. A number of characteristics of this species make it particularly good as an animal model.

Address reprint requests to Fred J. Karsch, RSP 300 N. Ingalls, 11 th floor, The University of Michigan, Ann Arbor, MI 48109-0404. 
One important attribute is its large body size and blood volume. This permits extensive serial sampling of blood for characterizing, in the same animal, the secretory profiles of hormones secreted by the gonads, anterior pituitary, hypothalamus, and pineal gland. An intricate interplay between these hormones, and corresponding changes in their secretory profiles, constitutes the endocrine basis of seasonal reproduction (Lincoln and Short, '80; Karsch et al., '84). One particular example which highlights the need to characterize hormone secretory profiles pertains to the pulsatile pattern of reproductive neuroendocrine function (see next section).

Another benefit is the relatively large size of the brain and cranium of the sheep. This has facilitated the development of complicated neurosurgical procedures to gain access to the neuroendocrine axis for the purpose of manipulating and monitoring neurosecretion. An example of this approach is provided by the recent study of Thiéry et al. ('89). These investigators made use of a locally applied neurotoxin for selective destruction of specific hypothalamic sites in an attempt to identify which sites contribute to the inhibition of gonadotropin secretion during the infertile, or anestrous, season of the ewe. The large size of the sheep brain was important here because it minimized limitations concerning relative area of spread of the micro-injected neurotoxin in comparison to that which would occur in animals having smaller brains. Also facilitated by the large size of the cranium is the ability to gain access to the hypothalamic-pituitary blood vascular system for sequential sampling of portal blood from fully conscious animals. This allows characterization of the secretory patterns of hypothalamic substances which govern seasonal changes in reproductive function (see next section).

Many other benefits of the sheep could be delineated, including its availability, docile nature, ease of handling, long life span which permits an evaluation of the role played by long-term circannual rhythms in the generation of seasonal reproductive cycles, and the existence of a wide variety of sensitive and specific assays for measurement of reproductive hormones. Correspondingly, the sheep also has its limitations as an animal model. For example, its large body size, which lends itself so nicely to neuroendocrine studies, makes it difficult to confine sheep in controlled environments for the purpose of identifying relevant environmental time cues, or the mechanisms through which those cues regulate the reproductive neuroendocrine axis. Further, its long gestation period ( 5 months) hinders the identification of genetic mutants, the development of inbred strains, and the use of genetic models, approaches which hold great promise for unravelling complex biological processes. Rather than focusing further on the attributes and limitations of this model, the following sections will highlight the use of the sheep in the area of the pulsatile function of the reproductive neuroendocrine axis, and why this is important in the determination of seasonal breeding cycles.

\section{PULSATILE PATTERNS OF REPRODUCTIVE NEUROENDOCRINE FUNCTION Pulses and seasonality}

It was 20 years ago that Dierschke et al. (70) first described episodic fluctuations of circulating luteinizing hormone $(\mathrm{LH})$ in the ovariectomized rhesus monkey. These oscillations, or pulses of LH as they are often called, have now been described in many species and they are readily demonstrable in the presence as well as the absence of the gonads (see Karsch, '87). Further, the characteristics of the LH pulses change markedly with the seasonal reproductive state and, in this context, they are critical to seasonal switches in fertility.

In sheep, the frequency of LH pulses is particularly important; high frequency is associated with periods of fertility and low frequency with times of infertility (Lincoln and Short, ' 80 ; Karsch et al., '84; Martin, '84; Foster et al. '86). One example of this in the female is the change in LH pulse frequency during the course of the late-luteal and follicular phases of the estrous cycle. At the time of regression of the corpus luteum, the frequency of LH pulses increases five- to tenfold; this provides the stimulus for the final stages of follicular maturation and the preovulatory increase in estradiol that elicits the LH surge (Baird, '78; McNeilly et al., '82; Karsch et al., '84). The increase in LH pulse frequency is thus required for the induction of the $\mathrm{LH}$ surge and the generation of the estrous cycle. During the anestrous season of the spring and summer, LH pulses occur but not frequently enough to support recurring estrous cycles (Scaramuzzi and Baird, '77; Karsch et al., '84).

From these observations, it is clear that an alteration in frequency of the pulsatile mode of $\mathrm{LH}$ secretion is crucial to seasonal breeding. Other 
studies have demonstrated that the changes in pulsatile LH secretion are regulated by seasonal swings in environmental photoperiod and that photoperiod can have two types of effects (Lincoln and Short, '80; Goodman et al., '82; Martin et al., '83; Bittman et al., '85; Robinson et al., '85). These two types of effects are illustrated schematically for the ewe in Figure 1. One effect is referred to as a shift in estradiol negative feedback. This can best be seen in ovariectomized ewes bearing constant release implants of estradiol. The pace of LH pulses in such animals changes markedly during the course of the year in the presence of the fixed negative feedback signal provided by the implant. The other effect of photoperiod has been referred to as direct photoperiodic drive. This is
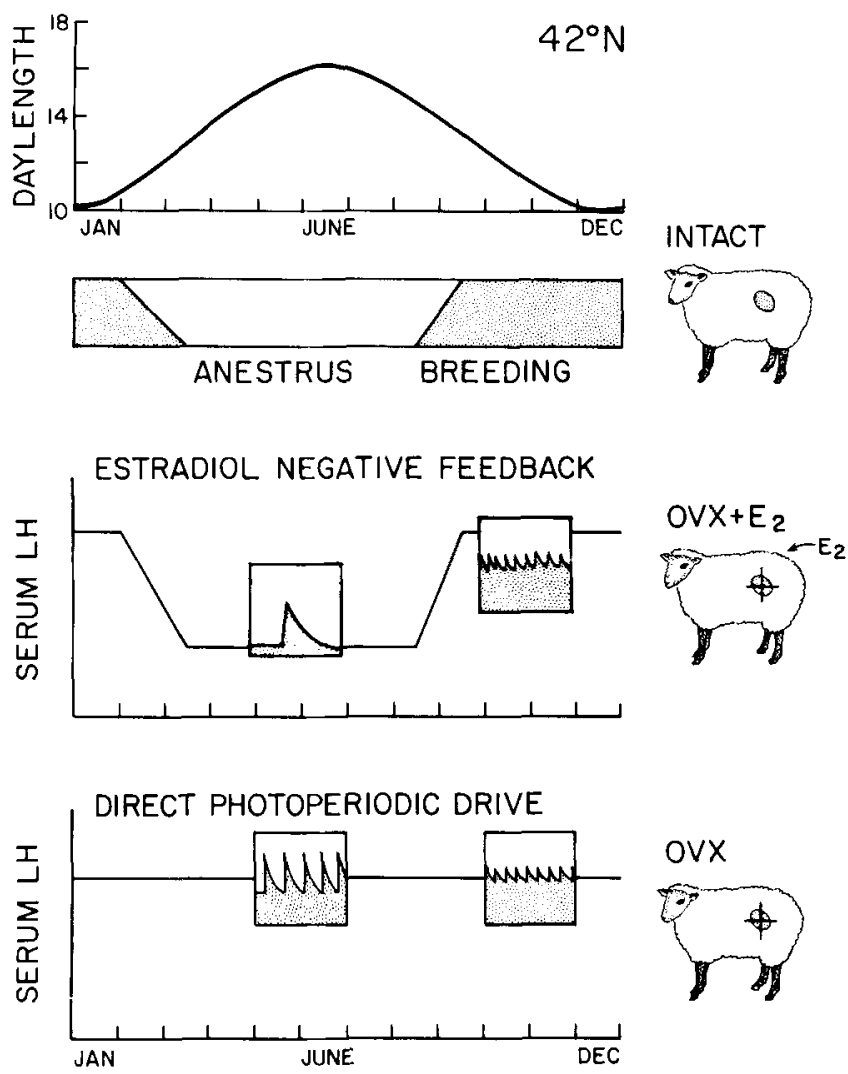

Fig. 1. Effects of photoperiod on seasonal breeding cycles in the ewe. Top shows the timing of the annual cycles of day length and of reproduction in Suffolk ewes maintained under natural environmental conditions in Ann Arbor, Michigan. (Shaded and open areas of horizontal bar indicate breeding and anestrous seasons, respectively.) Middle illustrates shifts in estradiol negative feedback, monitored by the pattern of LH secretion in ovariectomized (OVX) ewes bearing constant-release implants of estradiol $\left(\mathrm{E}_{2}\right)$. Bottom illustrates changes in direct photoperiodic drive, evaluated by the pulsatile pattern of $\mathrm{LH}$ secretion in ovariectomized ewes. Adapted from Robinson et al. ('85). demonstrable in ovariectomized ewes not treated with ovarian steroids, and thus is independent of gonadal secretions. In both instances, inductive photoperiod (decreasing day length, autumn) is associated with heightened frequency of $\mathrm{LH}$ pulses and inhibitory photoperiod (increasing day length, spring) with reduced frequency.

There is strong evidence to support the concept that changes in the ability of estradiol to regulate the frequency of $\mathrm{LH}$ pulses constitutes the primary neuroendocrine determinant of the seasonal onset and termination of estrous cycles in the ewe (Karsch et al., '84). When estradiol can lower the frequency, repeated estrous cycles are actively suppressed and the breeding season is "switched off." When estradiol, by itself, is unable to inhibit frequency, recurring estrous cycles are permitted and the breeding season is "switched on."

\section{Pulsatile GnRH secretion}

Although it is generally assumed that the pulsatile secretion of $\mathrm{LH}$ from the anterior pituitary gland is generated by a similar pulsatile discharge of gonadotropin-releasing hormone (GnRH) from the hypothalamus, few studies have actually documented this assumption, and none have provided an adequate description of seasonal changes in $\mathrm{GnRH}$ secretion. The reason for this is the extreme difficulty in monitoring GnRH secretion directly due to the inaccessibility of the hypophyseal portal vasculature. Further, it is inadequate to measure $\mathrm{GnRH}$ in the peripheral circulation because of the tremendous dilution and metabolism of hypophysiotropic substances once they leave the pituitary.

In 1982, two techniques were described for monitoring the time course of $\mathrm{GnRH}$ secretion in conscious ewes. One technique involved collection of extracellular fluid in the region of GnRH terminals in the median eminence. With this procedure $\mathrm{GnRH}$ was measured in sequential samples obtained every 10 minutes for 5 to 7 hours by pushpull perfusion (Levine et al., ' 82 ). The other procedure involved sequential sampling of pituitary portal blood (Clarke and Cummins, ' 82 ). With this procedure, two parallel guide tubes were surgically implanted such that their internal openings were adjacent to the portal vessels that course along the anterior face of the pituitary. Both guide tubes were exteriorized to permit access to the portal vasculature once the ewe recovered from surgery. For collection of portal blood, the ewe was heparinized and a stylette was introduced into one guide tube to lesion a relatively 
small portion of the portal vasculature. The portal blood that flowed from the lesioned vessels was then aspirated continuously from the second guide tube to determine the secretory pattern of GnRH. A benefit of each of these techniques is that pituitary function is not disrupted, and thus, the time courses of both hypothalamic and pituitary secretions can be monitored simultaneously in the same animal.

Recently the technique for portal blood collection was refined by Caraty and Locatelli ('88). An important improvement was the placement of a collection cone between the pituitary and the collection cannula to form an airtight seal. This prevents both loss of portal blood and leakage of peripheral blood into the collection site. This procedure has allowed sequential 10 minute samples of portal blood to be obtained for up to 48 hours (Caraty, Moenter, Locatelli, and Karsch, unpublished).

The temporal relationship between the pulsatile secretion of $\mathrm{LH}$ and GnRH has been examined in gonadectomized sheep by using each of the above procedures (Levine et al., ' 82 ; Clarke and Cummins, '82; Caraty and Locatelli, '88). An example of the type of data that can be obtained is illustrated in Figure 2; this describes the secretory profiles we have observed in an ovariectomized sheep by using the technique of Caraty and Locatelli ('88) for portal blood collection. Regardless of the procedure employed, each pulse of LH secreted by pituitary was found to be accompanied by a pulse of GnRH from the hypothalamus. The converse relationship, however, was not uniformly observed. Specifically, pulses of GnRH not accompanied by LH pulses (i.e., "silent GnRH pulses") were reported by Clarke and Cummins ('82) and by Levine et al. ('82); such silent pulses of GnRH were not observed by Caraty and Locatelli ('88) nor have they been seen by Karsch et al. ('87).

Since the initial description of the secretory patterns of $\mathrm{GnRH}$ in the ovariectomized ewe, several studies in this area have been published, but progress has been slow due to the technical demands of the procedures and difficulties in obtaining adequate sets of data. As of this (autumn 1988), two reports have described GnRH secretory patterns during the estradiol-induced LH surge (Clarke and Cummins, '85; Schillo et al., '85); another described GnRH during the estrous cycle (Clarke et al., '87); two studies examined effects of an antagonist of endogenous opiate peptides in the ram (Caraty et al., '87) and the ewe (Horton et

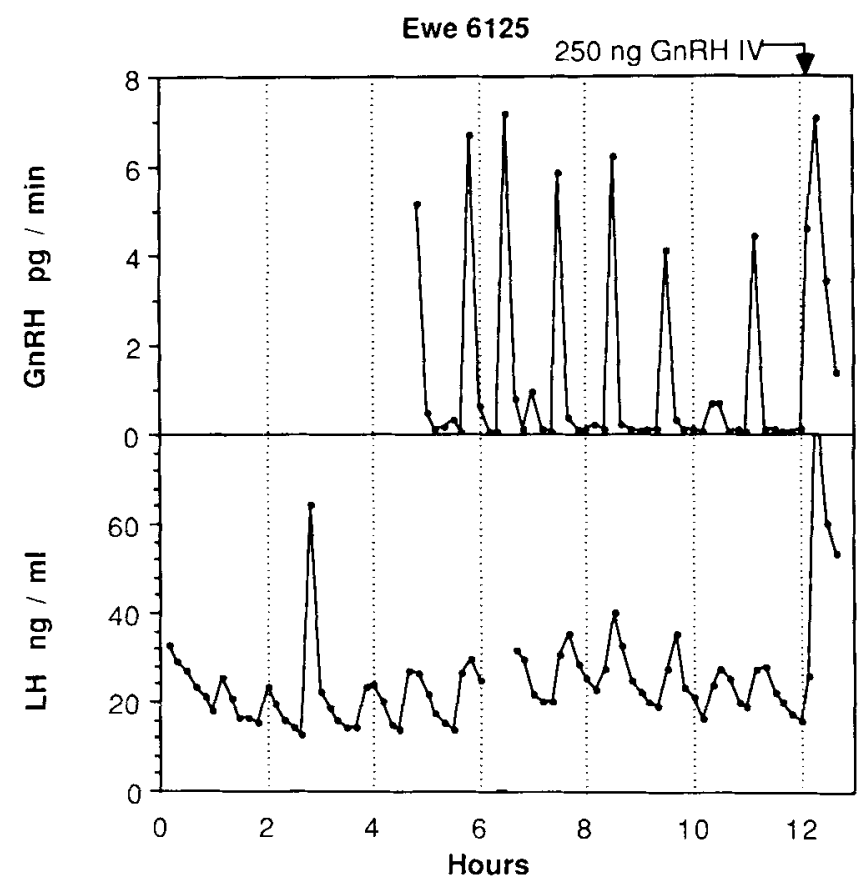

Fig. 2. Pulsatile secretion of gonadotropin-releasing hormone (GnRH, top) and luteinizing hormone ( $\mathrm{LH}$, bottom) in an ovariectomized ewe. (This ewe was also thyroidectomized.) LH was measured in blood samples obtained from the jugular vein every 10 minutes; $\mathrm{GnRH}$ was determined at corresponding times in portal blood samples by the method of $\mathrm{Ca}-$ raty and Locatelli (' 88 ). At the end of the sampling period, an intravenous bolus of GnRH was injected (arrow) to test pituitary responsiveness and to check the collection system for in vivo recovery of $\mathrm{GnRH}$. Missing values for $\mathrm{LH}$ represent samples that were lost. From Moenter and Karsch, unpublished.

al., '87); one reported on the effects of castration on GnRH release in the ram (Caraty and Locatelli, '88); and one paper described negative feedback effects of ovarian steroids (Karsch et al., '87). In the latter study, estradiol and progesterone were found to evoke a profound suppression of pulsatile $\mathrm{GnRH}$ release. An adequate test, however, remains to be performed to determine whether the seasonal change in response to estradiol negative feedback is due to a shift in the ability of the steroid to inhibit the pulsatile mode of GnRH release. Thus, while changes in pulsatile activity of the reproductive neuroendocrine axis constitute a primary determinant of the seasonal switches in fertility, seasonal changes in $\mathrm{GnRH}$ secretion remain to be established, characterized, and studied for their regulatory mechanisms and physiological importance.

\section{PERSPECTIVES AND APPROACHES FOR FUTURE RESEARCH}

In the last 15 years, large strides have been made in our understanding of the neuroendocrine 
regulation of seasonal reproductive cycles and, in this regard, the sheep has been an important animal model. It is clear, however, that progress made thus far merely scratches the surface of what is proving to be a complex area of regulatory biology. Investigators are now faced with the challenge of unravelling complex underlying mechanisms. We must turn our attention to characterizing the changes in pulsatile secretion of GnRH that lead to the seasonal switches in fertility and we must clarify the neural basis of these changes. Several approaches should prove to be especially useful for this endeavor. For example, the GnRH neurosecretory cells and their inputs are being described in neuroanatomical terms; modern techniques for in vivo monitoring of neurotransmitter inputs to GnRH neurons are being exploited; minute amounts of physiological and pharmacological substances are being locally applied to specific brain sites to identify important regulatory loci. Based on the attributes described in this report, the sheep should continue to be a valuable animal model for utilizing these approaches to gain a better understanding of the seasonal plasticity which occurs within the reproductive neuroendocrine axis.

\section{ACKNOWLEDGMENTS}

Support for this report was provided by the NIH (HD-18337), the NSF (DCB-8710099), and the Department of Physiology at The University of Michigan. We thank Barbara Pearlman for help in the manuscript preparation.

\section{LITERATURE CITED}

Baird, D.T. (1978) Pulsatile secretion of LH and ovarian estradiol during the follicular phase of the sheep estrous cycle. Biol. Reprod., 18:355-364.

Bittman, E.L., A.H. Kaynard, D.H. Olster, J.E. Robinson, S.M. Yellon, and F.J. Karsch (1985) Pineal melatonin mediates photoperiodic control of pulsatile luteinizing hormone secretion in the ewe. Neuroendocrinology, 40:409418.

Caraty, A., and A. Locatelli (1988) Effect of time after castration on secretion of LHRH in the ram. J. Reprod. Fertil., 82:263-269.

Caraty, A., A. Locatelli, and B. Schanbacher (1987) Augmentation par la naloxone de la fréquence et de l'amplitude des pulses de LH-RH dans le sang porte hypothalamohypophysaire chez le bélier castré. C. R. Acad. Sci. [III], 305:369-374.

Clarke, I.J., and J.T. Cummins (1982) The temporal relationship between gonadotropin releasing hormone (GnRH) and luteinizing hormone $(\mathrm{LH})$ secretion in ovariectomized ewes. Endocrinology, 111:1737-1739.

Clarke, I.J., and J.T. Cummins (1985) Increased gonadotropin-releasing hormone pulse frequency associated with estrogen-induced luteinizing hormone surges in ovariectomized ewes. Endocrinology, 116:2376-2383.
Clarke, I.J., G.B. Thomas, B. Yao, and J.T. Cummins (1987) GnRH secretion throughout the ovine estrous cycle. Neuroendocrinology, 46:82-88.

Dierschke, D.J., A.N. Bhattacharya, L.E. Atkinson, and E. Knobil (1970) Circhoral oscillations of plasma LH levels in the ovariectomized rhesus monkey. Endocrinology, 87:850853.

Foster, D.L., F.J. Karsch, D.H. Olster, K.D. Ryan, and S.M. Yellon (1986) Determinants of puberty in a seasonal breeder. Recent Progr. Horm. Res., 42:331-384.

Goodman, R.L., E.L. Bittman, D.L. Foster, and F.J. Karsch (1982) Alterations in the control of luteinizing hormone pulse frequency underlie the seasonal variation in estradiol negative feedback in the ewe. Biol. Reprod., 27:1580-1589.

Horton, R.J.E., J.T. Cummins, and I.J. Clarke (1987) Naloxone evokes large-amplitude GnRH pulses in luteal-phase ewes. J. Reprod. Fertil. 81:277-286.

Karsch, F.J. (1987) Central actions of ovarian steroids in the feedback regulation of pulsatile secretion of luteinizing hormone. Annu. Rev. Physiol., 49:365-382.

Karsch, F.J., E.L. Bittman, D.L. Foster, R.L. Goodman, S.J. Legan, and J.E. Robinson (1984) Neuroendocrine basis of seasonal reproduction. Recent Progr. Horm. Res., 40:185232.

Karsch, F.J., J.T. Cummins, G.B. Thomas, and I.J. Clarke (1987) Steroid feedback inhibition of pulsatile secretion of gonadotropin-releasing hormone in the ewe. Biol. Reprod., $36: 1207-1218$.

Levine, J.E., K.-Y.F. Pau, V.D. Ramirez, and G.L. Jackson (1982) Simultaneous measurement of luteinizing hormonereleasing hormone and luteinizing hormone release in unanesthetized, ovariectomized sheep. Endocrinology, 111: 1449-1455.

Lincoln, G.A., and R.V. Short (1980) Seasonal breeding: Nature's contraceptive. Recent Progr. Horm. Res., 36:1-43.

Martin, G.B. (1984) Factors affecting the secretion of luteinizing hormone in the ewe. Biol. Rev., 59:1-87.

Martin, G.B., R.J. Scaramuzzi, and J.D. Henstridge (1983) Effects of oestradiol, progesterone, and androstenedione on the pulsatile secretion of luteinizing hormone in ovariectomized ewes during spring and autumn. J. Endocrinol., $96: 181-193$.

McNeilly, A.S., M. O'Connell, and D.T. Baird (1982) Induction of ovulation and normal luteal function by pulsed injections of luteinizing hormone in anestrous ewes. Endocrinology, 110:1292-1299.

Robinson, J.E., H.M. Radford, and F.J. Karsch (1985) Seasonal changes in pulsatile luteinizing hormone (LH) secretion in the ewe: Relationship of frequency of $\mathrm{LH}$ pulses to day length and response to estradiol negative feedback. Biol. Reprod., 33:324-334.

Scaramuzzi, R.J., and D.T. Baird (1977) Pulsatile release of luteinizing hormone and the secretion of ovarian steroids in sheep during anestrus. Endocrinology, 101:1801-1806.

Schillo, K.K., L.S. Leshin, D. Kuehl, and G.L. Jackson (1985) Simultaneous measurement of luteinizing hormonereleasing hormone and luteinizing hormone during estradiol-induced luteinizing hormone surges in the ovariectomized ewe. Biol. Reprod., 33:644-652.

Thiéry, J.-C., G.B. Martin, Y. Tillet, M. Caldani, M. Quentin, C. Jamain, and J.-P. Ravault (1989) Role of hypothalamic catecholamines in the regulation of luteinizing hormone and prolactin secretion in the ewe during seasonal anestrus. Neuroendocrinology 49:80-87. 